\title{
Asılı ve tek damla yöntemiyle liyotropik sıv1 kristallerde yüzey gerilimlerinin belirlenmesi
}

\author{
PInar ÖZDEN*, Nejmettin AVCI \\ Muğla Sıtkı Koçman Üniversitesi, Fen Fakültesi, Fizik Bölümü, MUĞLA \\ Geliș Tarihi (Recived Date): 21.09.2017 \\ Kabul Tarihi (Accepted Date): 06.12.2017
}

Özet

Liyotropik sıvı kristaller kimyasal temizleyicilerden organik sıvılara kadar pek çok bileşiğin temel yapısını oluşturmaktadır. Kolloidal özelikleri nedeniyle bu malzemelerin yüzey gerilimlerinin belirlenmesi uygulama alanları için büyük önem taşımaktadır. Sıvıların yüzey gerilimlerinin belirlenmesi için birçok teknik bulunmaktadır. Asılı ve tek damla teknikleri, uygulama kolaylı̆̆ı yanında doğru sonuçlar vermesiyle de öne çıkmaktadır. Bu çalışmada amfifil tabanlı liyotropik sıvı kristaller farklı konsantrasyonlarda hazırlanarak asılı damla ve tek damla teknikleriyle ile yüzey gerilimleri belirlenmiştir. Ayrıca bu örnekler için farklı yüzeylerde değme açısı ve yüzey serbest enerji değerleri hesaplanmıştır. Sıvı kristal moleküllerin yüzeyle yaptıkları açıya bağlı olarak bu parametrelerin değiş̧iği gözlenmiştir.

Anahtar Kelimeler: Liyotropik sıvı kristal, yüzey gerilimi, asılı damla, tek damla.

\section{Determination of surface tension in lyotropic liquid crystals with the pendant and sessile drope method}

\begin{abstract}
Lyotropic liquid crystals form the basic structure of many compounds from chemical cleaners to organic liquids. The determination of surface tension of these materials is of great importance for application due to their colloidal properties. There are a lot of techniques for determining the surface tension of liquids. Pendant and sessile drop techniques come not only forward with ease of application but also with accurate results. In this study, amphiphile-based on lyotropic liquid crystals were prepared at different concentrations and surface tension of those was determined by pendant drop and sessile drop techniques. Besides, the values of tilt angle and surface free energy were calculated by changing surfaces for these samples. It has been observed that change in these parameters depends on the angle of the surface of the liquid crystal molecules.
\end{abstract}

Keywords: Lyotropic liquid crystals, surface tension, pendant drop, sessile drop

\footnotetext{
*Pınar ÖZDEN, pozden@mu.edu.tr, https://orcid.org/0000-0001-5308-2060 Nejmettin AVCI, navci@mu.edu.tr, https://orcid.org/0000-0001-9189-1176
} 


\section{Giriş}

Liyotropik sıvı kristaller iki veya daha çok bileşenlerden oluşmuş üç boyutlu polimoleküler yapı birimlerine sahiptir. Liyotropik siv1 kristallik sistemler, hidrofilik (polar) ve hidrofobik (apolar) özelliğe sahip amfifil adı verilen kimyasal bileşik tabanlı çözeltilerdir. Yüzeysel etkin malzemeler olan amfifil malzemeler sabun ve deterjanların yapı maddeleridir [1].

Moleküllerinde taşıdıkları polar ve apolar gruplar nedeniyle yüzey etkin maddeler, bulundukları ortamlardaki yüzeylerde özel bir diziliş ile yerleşerek yüzey gerilimini düşürmektedirler. Yüzey etkinmadde çözeltilerinin yüzey gerilimi, artan derişim ileazalır ve daha sonra sabitleşir. Sabunlar, deterjanlar vs. suyun yüzeyindeki hidrojen bağlarını bozarak suyun diğer maddeleri 1slatma yeteneğini azaltır. Moleküller arası kuvvetleri zayıflatmak yüzey gerilimini azaltır. Yüzey gerilimi, yüzeyin 1 $\mathrm{cm}^{2}$ artırılması için birim uzunluğa uygulanan kuvvet olarak tanımlanmaktadır. Yüzey geriliminin birimi SI sisteminde $\mathrm{mN} / \mathrm{m}$ CGS sisteminde ise dyn/cm'dir. Yüzey gerilimibir sıvının yüzey alanını arttırmak için gerekli enerji olarakta tanımlanabilir. Sıvıların yüzey gerilimi sıv1 tanecikleri arası kuvvetlere ve sıcaklığa bağlı olarak değişir. Çoğu sıvı için yüzey gerilimi sıcaklık artışıyla yaklaşık doğrusal olarak azalır ve moleküller arası kohezyon kuvvetleri sıfıra yaklaştığında, kritik sıcaklık bölgesinde çok küçük olur [2].

Sivıların ve termotropik sıvı kristallerin yüzey gerilimlerinin belirlenmesi için uzun yıllardır farklı teknikler geliştirilmiştir [3-11]. Ancak liyotropik sıv1 kristallerin yüzey gerilimleri hakkında literatürde yeterli bilgi bulunmamaktadır. Bu çalışmada amfifil tabanlı liyotropik sıvı kristallerin asılı damla ve tek damla teknikleriyle ile yüzey gerilimlerinin belirlenmesi ve farklı yüzeylerde değme açısı ve yüzey serbest enerji değerleri hesaplanması amaçlanmıştır. Asılı ve tek damla yöntemleri, uygulama kolaylığı yanında doğru sonuçlar vermesiyle de öne çıkmaktadır. Önerilen bu yöntem liyotropik sıvı kristaller için ilk kez bu çalışmada sunulmuştur. Bu çalışmanın amacı literatürdeki bu boşluğu doldurmak ve ileride bu konuda yapılacak olan çalışmalara yol gösterici literatür bilgisi ortaya koymaktır.

\section{Metot}

$\mathrm{Bu}$ çalışmada, liyotropik sıvı kristallerin yüzey geriliminin belirlenmesi için farklı kontransyonlarda hazırlanan örnekler Asılı ve Tek Damla Yöntemi kullanılmıştır. Mikro terazi, kapiler basınç, kapiler ve yerçekimi kuvvetleri arası oran, yerçekimi etkisindeki damla bu yöntemlerin önde gelenleridir.
Bu çalışmada yüzey gerilimi belirlenecek sıvının bir damlasının yer çekimi etkisi altındaki şeklini temel alan son yöntem kullanılmıştır [3]. Yer çekimi altındaki damla yöntemi kendi içerisinde asılı damla ve tek damla metodu olarak ikiye ayrılır. Asılı damla yönteminde bir uç içerisinden serbest düşmeye bırakılan damlanın üst $(d)$ ve orta bölümdeki (D)çapı ölçülerek yüzey gerilimi, $\gamma$,

$\gamma=\frac{\Delta \rho \mathrm{gD}^{2}}{\mathrm{H}}$

denklemiyle hesaplanabilir. Burada $\Delta \rho \quad\left(\mathrm{g} / \mathrm{cm}^{3}\right)$ yüzey ve ortam arasındaki yoğunluk farkını, $g$ $\left(\mathrm{cm} / \mathrm{s}^{2}\right)$ yerçekimi ivmesini ifade etmektedir. Damla şekline bağlı olan parametre $H$ şekil faktörü olan $S=d / D$ ile orantılıdır ve hem $S$ hem de $1 / H$ değer çiftlerini gösteren tablolar bulunmaktadır. $\mathrm{Bu}$ tablo değerleri yanında deneysel olarak elde edilmiş olan

$1 / \mathrm{H}=\mathrm{B}_{4} / \mathrm{S}^{\mathrm{a}}+\mathrm{B}_{3} \mathrm{~S}^{3}-\mathrm{B}_{2} \mathrm{~S}^{2}+\mathrm{B}_{1} \mathrm{~S}-\mathrm{B}_{0}$

formülü kullanılarak da $1 / H$ değerleri bulunabilir. Burada B değerleri yine deneysel olarak bulunmuş sabitlerdir [4].

Tek Damla yönteminde ise katı bir alttaş üzerine konulmuş olan bir damlanın şekline bağlı olarak yüzey gerilimi belirlenir. Bu yöntem için sıvı miktarı az olan ve kontak açısı $90^{\circ}$ 'den büyük damlaların kullanılması önerilir. $\mathrm{Bu}$ yöntemde temel olarak önce yüzey üzerindeki damlanın ekvator çizgisi belirlenir ve üst noktadan bu noktaya kadar olan uzaklık $z_{e}$ ölçülür. Daha sonra

$\gamma=\frac{\Delta \rho g z_{e}}{2}$

kullanılarak yüzey gerilimi belirlenir [3].

\section{3. Örneklerin hazırlanması}

$\mathrm{Bu}$ çalışmada iki ve üç bileşenli liyotropik sıvı kristalik sistemler incelenmiştir. İki bileşenli sistemler amfifil + su, üç bileşenli sistemler amfifil $+\mathrm{su}+$ alifatik alkol şeklindedir. Amfifil olarak Tetradesiltrimetilamonyum $\quad$ Bromür $\left(\mathrm{C}_{17} \mathrm{H}_{38} \mathrm{NBr}-\right.$ TDTMABr) "Roth" firmasından \%99 saflıkta satın alınarak kullanılmıştır. Alifatik alkol olarak ise yüksek saflılığa sahip decanol (DeOH) Merck firmasından alınmıştır ve su $\left(\mathrm{H}_{2} \mathrm{O}\right)$, üç kere distille ve deionize edilmiş olarak kullanılmıştır. Farklı konsantrasyonlarda hazırlanan iki ve üç bileşenli sistemler steril şırıngalara doldurularak asılı ve tek damlacıklar oluşturulmuştur. Örnekler konsantrasyon oranlarına göre; T1: \%32 TDTMABr $+\% 68 \mathrm{H}_{2} \mathrm{O}$, T2: \%29.6 TDTMABr + \%65.9 $\mathrm{H}_{2} \mathrm{O}+$ $\% 4.5 \mathrm{DeOH}, \mathrm{T} 3: \% 40 \mathrm{TDTMABr}+\% 50 \mathrm{H}_{2} \mathrm{O}+$ 
$\% 10 \mathrm{DeOH}, \mathrm{T} 4: \% 40$ TDTMABr $+\% 55 \mathrm{H}_{2} \mathrm{O}+\% 5$ DeOH şeklinde kodlanmıştır.

Asılı damlaların oluşturulması için seçilen örneklerle ve farklı şırıngalarla denemeler yapılmış $0.4 \mathrm{~mm}$ çapa sahip şırıngaların en uygun sonuçları verdiği belirlenerek bu uçlarla ölçümler gerçekleştirilmiştir. Tek damla yöntemi için ise düz cam ve farklı yönlerde yöneltilmiş cam alt yüzeyler üzerine uygun küre şekli oluşacak şekilde örnekler damlatılmıştır. İki yöntem için de oluşan damlaların ölçümlerinin yapılması için tripod üzerine yerleştirilmiş Olympus OMD EM10 kameraya takılmış Panasonic $20 \mathrm{~mm}$ f1.7 objektif önüne yerleştirilmiş Raynox makro lens eklentisi ile ayrıntılı fotoğrafları çekilmiştir. Elde edilen görüntüler farklı fotoğraf işleme yazılımları kullanılarak gerekli ölçüm ve hesaplamalar yapılmıştır.

Tek damla yönteminde kullanılan farklı yönlerde yöneltilmiş camlar için sandviç hücreler aşağıdaki şekilde gibi hazırlanmıştır. İlk olarak, şeffaf cam, deterjanlı su çözelti ile dolu bir ultrasonik banyoda 30 dakika boyunca bekletilmiştir. Daha sonra, cam tabaka deionize su ile durulanmıştır ve izopropanol ile yıkanmıștır ve $60{ }^{\circ} \mathrm{C}$ 'de kurutulmuștur. Bu cam yüzeylerde planar yönelim elde etmek için PI2555 (HD Microsystems) ve T9039 (HD Microsystems) polymideler ile $1 / 4$ oranında çözelti hazırlanmıştır ve 300rpm/dakika hızındaki spin kaplama cihazıyla çözelti homojen bir şekilde cam yüzeyinde dağıtılmıştır. Kaplanan cam yüzey üzerinde 10 nm'lik ince bir film oluşturulmuştur. $\mathrm{Bu}$ filmin kalınlığı hazırlanan çözeltinin oranına göre değişmektedir. Daha sonra bir dakika süreyle $90^{\circ} \mathrm{C}$ 'de yumuşak 1 sıl işlem yapılmış ve buna ek olarak 1 saat süre ile $275^{\circ} \mathrm{C}^{\prime}$ de sert 1 sıl işleme tabi tutulmuştur. Daha sonra PI2555 kaplı cam yüzeyler 800-850 Pa basınca sahip bir bloğa sarılı temiz bir kadife kumaş kullanılarak belirlenen tek bir yön boyunca en az 10 defa sürtülmüştür. Homeotropik yönelim için ise SI1211 (HD Microsystems) ve T9039 (HD Microsystems) polymideler ile 1/3 oranında çözelti hazırlanmış ve 300rpm/dakika hızındaki spin kaplama cihazıyla çözelti homojen bir şekilde cam yüzeyinde dağıtılmıştır. Kaplanan cam yüzey üzerinde 15 nm'lik ince bir film oluşturulmuştur. Spin-kaplama tekniği ve bu çözeltiyi kullanılarak cam yüzeyinde ince bir homeotropik tabaka oluşturulmuştur. Daha sonra bir dakika süreyle $90^{\circ} \mathrm{C}$ 'de yumuşak 1 sıl işlem yapılmış ve buna ek olarak 1 saat süre ile $180^{\circ} \mathrm{C}$ 'de sert 1 sil işlem uygulanmıştır [12].

\section{Araştırma bulguları}

Ölçümler için farklı konsantrasyonlarda hazırlanan örneklerin şırınga ucunda oluşan damla şekilleri Şekil 1'de gösterilmiştir. Bu sonuçlara göre farklı konsantrasyon oranlarında damla şekli belirgin biçimde değişmektedir. Asılı damla yöntemiyle sonuçların incelenmesi için Hansen\&Rodsrud denklemi kullanılmıştır [13]. Bu denklem deneysel veriler kullanılarak elde edilmiştir ve yüzey gerilimi hesabı için gerekli katsayıları doğruya en yakın sonuçları veren ifadelerden biridir. Yüzey gerilimi $\gamma$, yoğunluk farkı $\Delta \rho$, damlanın küresel kısmının çapı $R_{0}(\mathrm{~cm})$, yerçekimi ivmesi $g\left(\mathrm{~cm} / \mathrm{s}^{2}\right), \mathrm{D}_{\mathrm{s}}(\mathrm{cm})$ ile $\mathrm{D}_{\mathrm{e}}(\mathrm{cm})$ damla şeklinden elde edilen parametreler olmak üzere Hansen\& Rodsrud denklemi

$$
\frac{\Delta \rho g R_{0}^{2}}{\gamma}=0.12836-0.7577 \frac{D_{s}}{D_{e}}+1.7713\left(\frac{D_{s}}{D_{e}}\right)^{2}-0.5426\left(\frac{D_{s}}{D_{e}}\right)^{3}
$$

şeklinde ifade edilir [13].

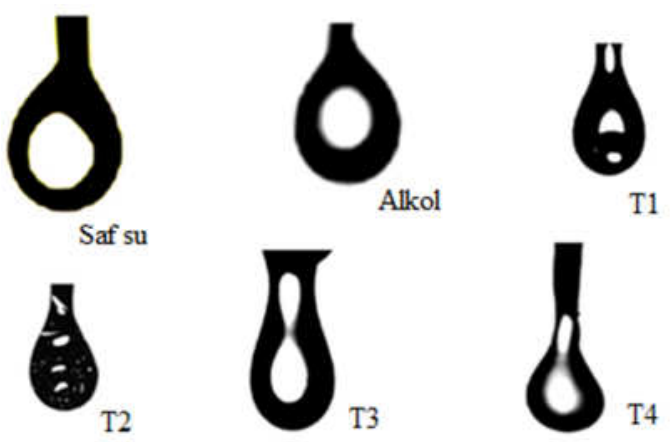

Şekil 1. Farklı konsantrasyonlardaki malzemeler için oluşan damla şekilleri.

Her bir damla formu için Şekil 2'de görülen bölümlerden ImageJ görüntü işleme programı ile ölçümler yapılmış ve elde edilen sonuçlar Tablo 1 'de verilmiştir. Bu tabloda ayrıca incelemesi yapılan malzemelerin yoğunluk değerleri, havanın yoğunluğundan farkları ve çap değerleri de verilmiştir. Kullanılan yöntemin güvenilirliği etil alkol ve saf su üzerinden yapılan ölçümlerle de kontrol edilmiştir.

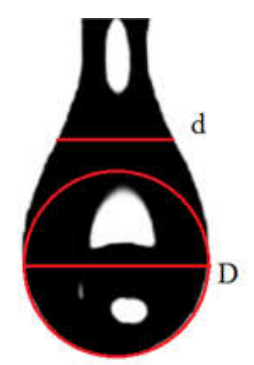

Şekil 2. Örnek damla formu için ölçümü yapılan parametreler (serbest düşmeye bırakılan damlanın üst $(d)$ ve orta bölümdeki $(D)$ çapı).

Yüzey gerilimi değerleri incelendiğinde amfifil, su ve dekanol konsantrasyonlarına bağlı olarak farklı değerler elde edilmiştir. 
Tablo 1.Asılı damla yöntemiyle incelenen örnekler için kullanılan ve hesaplanan parametreler.

$$
W_{s l}=\gamma_{l v}(1+\cos \theta)
$$

\begin{tabular}{|c|c|c|c|c|c|c|c|}
\hline Örnek & $\begin{array}{l}\rho_{\text {malzeme }} \\
\left(\mathrm{g} / \mathrm{cm}^{3}\right)\end{array}$ & $\Delta \rho$ & $\mathrm{D}_{\mathrm{s}}$ & $\mathrm{D}_{\mathrm{e}}$ & $\mathrm{R}_{0}(\mathrm{~m})$ & $\begin{array}{c}\text { Yüzey } \\
\text { gerilimi } \\
\gamma(\mathrm{dyn} / \mathrm{cm})\end{array}$ & ve yine Dupre' nin $[15,16]$ \\
\hline $\mathrm{T} 1$ & 1320 & 1318.775 & 27 & 34 & 0.00108 & 40.65 & \multirow[t]{2}{*}{$W_{s l}=2\left(\gamma_{l v} \gamma_{s v}\right)^{0.5}$} \\
\hline $\mathrm{T} 2$ & 893,74 & 892.515 & 22 & 30 & 0.00109 & 33.56 & \\
\hline $\mathrm{T} 3$ & 1017 & 1015.775 & 13 & 21 & 0.00098 & 46.66 & \multirow{2}{*}{ bağıntısı kullanılarak } \\
\hline $\mathrm{T} 4$ & 1170 & 1168.775 & 21 & 29 & 0.00101 & 39.52 & \\
\hline
\end{tabular}

Örneklerin incelenmesi için kullanılan bir diğer yöntem tek damla yöntemidir. Bu amaçla normal, planar ve homeotropik cam yüzeylere birakılan malzemeye ait tek bir damlanın oluşturduğu görüntüler Şekil 3'de verilmiştir. Şekil 3 incelendiğinde yine yüzey gerilimlerine ve cam yüzeyinin yönelimine bağlı olarak damla şekillerinin değiştiği görülmektedir. Görüntü işleme programları kullanılarak tüm tek damlaların temas açıları belirlenmiş ve Tablo 2'de verilmiştir.

Temas açıları kullanılarak yüzey gerilimi değerlerinin Zisman yöntemiyle hesaplanabildiği bilinmektedir [14]. Bu amaçla Young denklemi $[14,15]$,

$\gamma_{s v=} \gamma_{l v} \cos \theta+\gamma_{s l}$

Dupre denklemi $[14,16]$,

$\gamma_{s l}=\gamma_{s v}+\gamma_{l v}-W_{s l}$

Young - Dupre denklemi [14-16], $\gamma_{l v}(1+\cos \theta)=2\left(\gamma_{l v} \gamma_{s v}\right)^{0.5}$

ifadesi elde edilebilir. Bu eşitlikler kullanılarak dört örnek içinde yüzey serbest enerjisi ve yüzey gerilimi değerleri hesaplanmış Tablo 4 ve Tablo 5'te verilmiştir. Eşitlik 5-9' da kullanılan $\gamma_{l v}$ : sıvı yüzey enerjisi, $\gamma_{s v}$ : kat1 yüzey serbest enerjisi, $\gamma_{s l}$ : kat1 sıv1 ara yüzey serbest enerjisi, $W_{s l}$ de katı-sıv1 aras1 bağlanma enerjisidir ve bu parametreler damla üzerinde Şekil 4'te gösterilmiştir.

Tablo 2.Tek damla yöntemiyle belirlen temas açıs1 değerleri.

\begin{tabular}{lllll} 
Örnek & $\begin{array}{l}\text { Normal cam } \\
\text { yüzey } \\
\text { Temas açıs1 } \\
\left({ }^{\circ}\right)\end{array}$ & $\begin{array}{l}\text { Planar } \\
\text { yüzey } \\
\text { Temas } \\
\left({ }^{\circ}\right)\end{array}$ & $\begin{array}{l}\text { aç1S1 } \\
\text { cam yüzey } \\
\text { Temas aç1s1 } \\
\left({ }^{\circ}\right)\end{array}$ \\
\hline T1 & 37 & 54 & 65 \\
T2 & 26 & 46 & 59 \\
T3 & 47 & 82 & 92 \\
T4 & 28 & 49 & 58
\end{tabular}
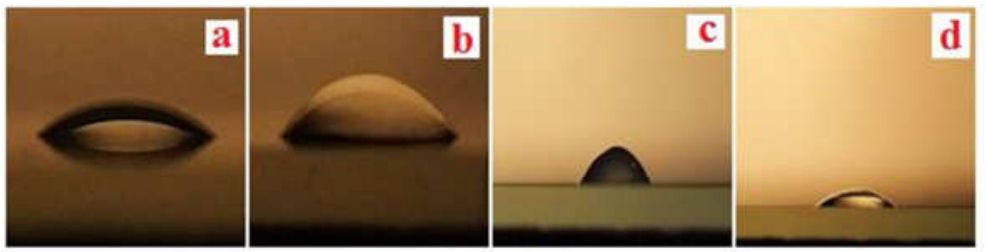

Normal Cam Yüzey
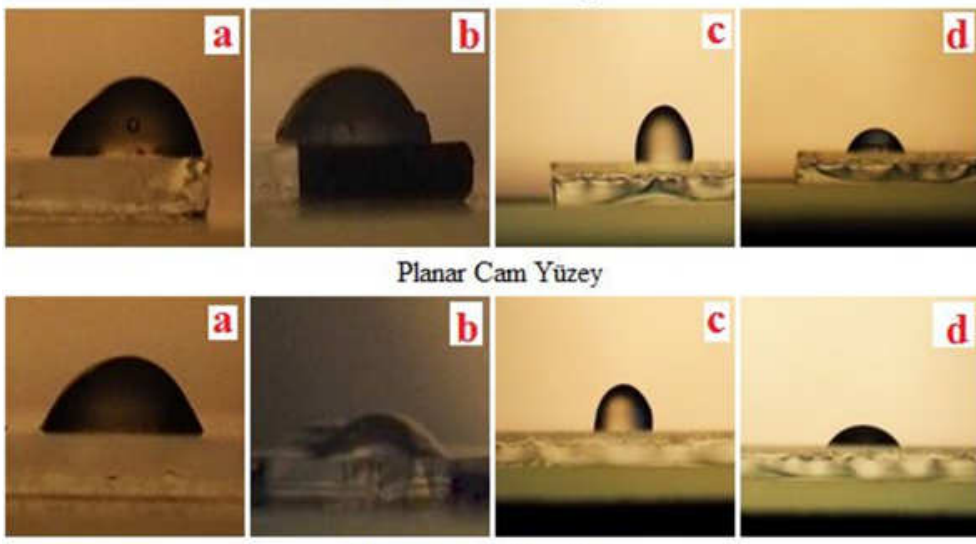

Homeotropik Cam Yüzey

Şekil 3. Tek damla yöntemiyle incelenen örnekler için sırasıyla normal, planar ve homeotrpik yönelimli cam yüzeylerde oluşan damla şekilleri (a. Örnek T1, b. Örnek T2, c. Örnek T3, d. Örnek T4). 


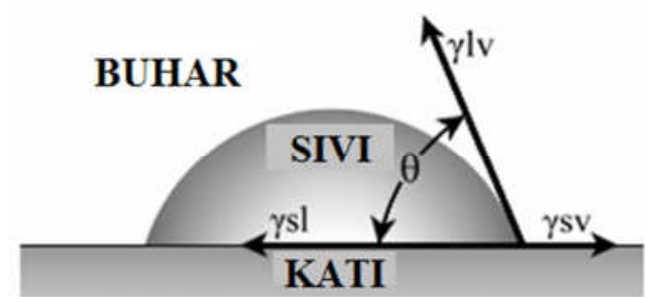

Şekil 4. Zisman yönteminde tek damla üzerinden belirlenen parametreler [17].

Tablo 3. Farklı yüzeylerde tek damla yöntemiyle hesaplanan yüzey gerilimi değerleri.

\begin{tabular}{cccc}
\hline Örnek & $\begin{array}{c}\text { Normal cam } \\
\text { yüzey } \\
\text { Yüzey gerilimi } \\
(\text { dyn/cm) }\end{array}$ & $\begin{array}{c}\text { Planarcam } \\
\text { yüzey } \\
\text { Yüzey gerilimi } \\
(\text { dyn/cm) }\end{array}$ & $\begin{array}{c}\text { Homeotropik } \\
\text { cam yüzey } \\
\text { Yüzey gerilimi } \\
(\text { dyn/cm) }\end{array}$ \\
\hline T1 & 40 & 46 & 50 \\
T2 & 36 & 43 & 48 \\
T3 & 43 & 56 & 60 \\
T4 & 37 & 44 & 47 \\
\hline
\end{tabular}

Tablo 4.Farklı yüzeylerde tek damla yöntemiyle hesaplanan yüzey serbest enerjisi değerleri.

\begin{tabular}{cccc}
\hline Örnek & $\begin{array}{c}\text { Normal cam } \\
\text { yüzey } \\
\text { Yüzey serbest } \\
\text { enerjisi } \gamma_{\mathrm{SV}} \\
\left(\mathrm{erg} / \mathrm{cm}^{2}\right)\end{array}$ & $\begin{array}{c}\text { Planarcam } \\
\text { yüzey } \\
\text { Yüzey serbest } \\
\text { enerjisi } \gamma_{\mathrm{SV}} \\
\left(\mathrm{erg} / \mathrm{cm}^{2}\right)\end{array}$ & $\begin{array}{c}\text { Homeotropikcam } \\
\text { yüzey } \\
\text { Yüzey serbest } \\
\text { enerjisi } \gamma_{\mathrm{SV}} \\
\left(\mathrm{erg} / \mathrm{cm}^{2}\right)\end{array}$ \\
\hline T1 & 32.35 & 28.99 & 25.30 \\
$\mathrm{~T} 2$ & 32.45 & 30.87 & 27.54 \\
$\mathrm{~T} 3$ & 30.41 & 18.17 & 13.97 \\
$\mathrm{~T} 4$ & 32.80 & 30.17 & 27.50 \\
\hline
\end{tabular}

\section{Kaynaklar}

[1] Özden, P., Sonlu Boyutlu Miselli Liyotropik Sıv1 Kristalik Mezofazların TermoMorfolojik, Termotropik, Termo-Optiksel ve Dielektrik Özelliklerinin İncelenmesi, Doktora Tezi, Muğla Sitkı Koçman Üniversitesi, Fen Bilimleri Enstitüsü, Muğla, (2017).

[2] Çelebi, N., Değim, T. ve Değim Z., 13. Yüzeylerarası Özellikler, Modern Farmasötik Teknoloji, Türk Eczacılar Birliği Eczacılık Akademisi Yayınları, 243 262, Ankara, (2009).

[3] Dukhin, S.S., Kretzchmar G. ve Miller, B., Dynamics of Adsorption at Liquid Interfaces: Theory, Experiment, Application, Elsevier, Amsterdam, 163 - 166, (2003).

[4] Drelich, J., Fang Ch. ve White C.L., Measurements of interfacialtension in fluid fluid systems, Encyclopedia of SurfaceandColloidScience, Marcel Dekker Inc., New York, (2002).

[5] Gannon, M., The surface tension of nematic liquid crystals, Philosophical Magazine A, 37, 117-135, (1978).

\section{Tartışma ve sonuç}

Tablo 1 ve Tablo 3'te elde edilen yüzey gerilimi değerleri karşılaştırıldığında asılı ve tek damla yöntemlerinden elde edilen değerlerin büyük bir uyum içerisinde olduğu görülmektedir. Bu sonuç iki yöntemin de sıv1 kristal malzemelerin yüzey gerilimlerinin belirlenmesinde büyük bir doğrulukla kullanılabileceğini göstermektedir. Cam yüzeylerinin yönelimlerinin etkisi göz önüne alındığında ise normal cam yüzeyde yüzey gerilimleri en düşük değerde iken planar yönelimde bu değer artmakta ve en yüksek değere homeotropik yönelmiş yüzeylerde ulaşılmaktadır. Yüzey serbest enerjisi değerlerinde ise tam tersi bir değişim söz konusudur. Liyotropik siv1 kristal malzeme içerisindeki misel yapıları ve bunların yüzeyle olan etkileşimlerinin sonucu bu durum ortaya çıkmaktadır. Özellikle endüstride temizleyici olarak yaygın kullanılan amfifil tabanlı liyotropik sıv1 kristallerin yüzey gerilimi değerleri uygulama açısından önemli olmaktadır. Farklı liyotropik malzeme oranları için farklı yüzey gerilimi değerleri elde edilebilir ve bu çalışmada önerilen tekniklerle bu değerler kolayca belirlenebilir.

[8] Chandrasekhar, S., Surface tension of liquid crystals, Molecular Crystals and Liquid Crystals, 2, 71-80, (1966).

[9] Krishnaswamy, S. ve Shashidhar, R., Measurement of the surface tension of CBOOA, Molecular Crystalsand Liquid Crystals, 38, 353-356,(1977).

[10] Stannarius, R. Ve Cramer, C., Surface tension measurements in freely suspended bubbles of thermotropic smectic liquid crystals, Liquid Crystals, 23, 3, 371-375, (1997).

[11] Tintaru, M., Moldovan, R., Beica, T. ve Frunza, S., Surface tension of some liquid crystals in the cyanobiphenyl series, Liquid Crystals, 28, 5, 793-797, (2001).

[12] Avc1, N., Çoklu Faz Geçişli Kalamitikve Bent-Core Moleküllü Sıv1 Kristallerin Termotropik, Termo-Morfolojik, Termo- 
Optiksel, Dielektrik ve Vizkoelastik Özelliklerinin İncelenmesi, Doktora Tezi, Muğla Sitk1 Koçman Üniversitesi, Fen Bilimleri Enstitüsü, Muğla, (2013).

[13] Hansen, F.K. ve Rodsrud, G., Surfacetensionby pendant drop. 1. A fast standard instrument using computer 1mage-analysis, Journal of Colloidand Interface Science, 141, 1-9, (1991).

[14] Zisman, W.A., Relation of the Equilibrium Contact Angleto Liquid and Solid Constitution. Advances in Chemistry, 43, 151, (1964).
[15] Young, T., III. An essay on the cohesion of fluids, Philosophical Transactions the Royal Society London, 1805 - 95, 65 - 87, (1805).

[16] Dupré, M.A., Théorie Méchanique de la Chaleur, 369, Gauthier - Villars, Paris, (1869).

[17] Clegg, C., ramé-hart Contact Angle Goniometers Newsletter, http://www.ramehart.com/newsletters/200807_news.htm (20.08.2017). 